\title{
Remote Support Sessions Help Living Atlas Developers Deploy Data Portal
}

\author{
Marie-Elise Lecoq ${ }^{\ddagger}$, Tim Robertson§, Cristina Villaverdel, Vicente José Ruiz Juradođ, Manash Shah\# \\ ‡ Living Atlases Community - VertNet, San Francisco, United States of America \\ $\S$ Global Biodiversity Information Facility, Copenhagen, Denmark \\ | Royal Botanic Garden - CSIC - GBIF Spain, Madrid, Spain \\ II Living Atlases Community - GBIF.es, Madrid, Spain \\ \# Swedish Museum of Natural History, Stockholm, Sweden
}

Corresponding author: Marie-Elise Lecoq (melecoq@vertnet.org)

Received: 03 Oct 2020 | Published: 06 Oct 2020

Citation: Lecoq M-E, Robertson T, Villaverde C, Ruiz Jurado VJ, Shah M (2020) Remote Support Sessions Help

Living Atlas Developers Deploy Data Portal. Biodiversity Information Science and Standards 4: e59275.

https://doi.org/10.3897/biss.4.59275

\begin{abstract}
Since the start of the Living Atlases community in 2013, participants have given us feedback on how to enhance our community. One of the recommendations was to simplify the deployment of a new Living Atlases data portal. As a result, the technical coordinator, Vicente J. Ruiz Jurado, of the Living Atlases community, designed a procedure that uses remote sessions to deploy a new Living Atlas instance at an institution.
\end{abstract}

Two options are available. The first one is dedicated to newcomers to help them understand how the Living Atlases modules work by installing a demo in several Virtual Machines, which are provided. The demo installation remains available for some weeks after the session to aid learning. The second option focuses on helping participants during their first deployment on their own production machines. We will explain both solutions during the presentation.

During this talk, we will also explore other tools that simplify the installation like the Living Atlases Ansible Generator. We will detail how this technical tool helps developers install chosen modules from the Atlas of Living Australia suite.

The feedback from those who have participated in these sessions will be shared. 
2

Lecoq $\mathrm{M}$ et al

Keywords

ALA, technical help

Presenting author

Manash Shah

Presented at

TDWG 2020 